\title{
versants
}

\section{Une statue à Divicot}

Henri ROoRDA

Écrivain

\begin{abstract}
Dans cette chronique de I920, Roorda donne libre cours à ses convictions pacifistes à partir de la figure de Divico, personnage de l'ancienne Helvétie nimbé de légende, dont il suggère ironiquement qu'il soit statufié pour être déclaré héros national et alimenter ainsi les sentiments guerriers chez les Suisses.
\end{abstract}

Keywords : Henri Roorda, guerre, pacifisme, Suisse, Divico, Charles Gleyre, Giovanni Giolitti.

Un jour, entre Fribourg et Morat, Divico fit passer les Romains "sous le joug”. S'il faut en croire le tableau du peintre Gleyre, la cérémonie amusa beaucoup les enfants de la région. Jamais la Suisse ne remporta une victoire plus éclatante sur les armées de M. Giolitti. Les plus primaires de nos écoliers en parlent entre eux, avec une émotion patriotique, à l'heure où le soir tombe. Et, pourtant, Divico attend encore sa statue. J'ai des raisons de croire qu'il l'attend sans aucune impatience. Mais la question n'est pas là. C'est pour ennoblir l'âme des vivants qu'on élève des monuments aux morts.

L'heure est grave. Depuis le jour néfaste de l'Armistice, notre âme est retombée dans sa torpeur. Du mois d'août 19I4, jusqu'au II novembre I9I8, nous avons lu quotidiennement les "communiqués" et nous avons eu sans cesse des paroles martiales. Aujourd'hui, nous consultons le cours de la Bourse et nous nous lamentons parce que la vie est chère !! Si ce n'était pas si triste, je dirais que c'est puant.

Seule, une nouvelle guerre mondiale pourra sauver l'âme humaine. Cette guerre, les meilleurs de nos concitoyens l'attendent. Ils s'y préparent. Ils dansent sans arrêt afin d'avoir le jarret solide lorsque le clairon les appellera. Mais c'est à notre peuple tout entier qu'il faut redonner la conscience de ce qu'il est réellement. Obligeons-le à regarder nos héros nationaux, pour qu'il se reconnaisse en eux.

Chers frères, chères sœurs, Divico est notre gloire militaire la plus pure. C'est, dans toute la force du terme, un homme "de chez nous". Né à Lutry, à une époque très ancienne que les professeurs vous indiqueront sans hésiter, il se montra bientôt de première force dans l'art de divicogner sur ses ennemis. Il faut absolument qu'il ait sa statue. Nous allons constituer un Divicomité d'Initiative et nous demanderons à chaque patriote sa divicotisation.

Et, pour commencer, réparons une erreur. Cela a été reconnu bien des fois : c'est aux fautes des copistes du Moyen Âge que beaucoup de noms propres doivent leur orthographe actuelle. La terminaison "co" n’a rien de 
romand. Notre vaillant peuple, très attaché à sa terre natale, se défie des noms étrangers. Eh bien, qu'il le sache : le nom de notre héros se terminait autrefois par un "t". C'est à un Divicot de Lutry que nous voulons élever un monument. Ne nous sentirions-nous pas beaucoup plus près de certains hommes illustres, dignes de notre vénération, si leurs noms s'écrivaient : Rabelet, Victor Hugot, Césart et Pompet, Boudat, Edgar Pot ? Il n'y a pas à dire : notre "t" final donne aux noms de famille un caractère bien vaudois.

Sur la vie privée de Divicot, les renseignements précis nous manquent. Nous savons seulement que, dans l'intimité, ses deux femmes, "la fougueuse Héloïse et la grosse Bertha", l'appelaient : Divicoco. Mais cela ne suffit pas pour que l'image du guerrier nous apparaisse nettement. Nous voudrions donner à notre peuple un Divicot ressemblant, comment faire ? En fait de documents, nous ne possédons que le tableau de Gleyre. Celui-ci essaya de mettre sur le visage de son héros la mâle expression d'un chef Helvète. Il recommença vingt fois ; mais, chaque fois, son Divicot ressemblait à un pasteur calviniste. Seule, la moustache était gauloise. Le peintre eut alors l'idée ingénieuse de cacher derrière le bras du guerrier son visage difficile à reproduire. Il savait bien que le spectateur essaierait vainement d'aller regarder de l'autre côté. De l'autre côté des tableaux, les yeux qu'on ouvre ne voient pas grand-chose. Malheureusement, une statue est un tableau autour duquel les imbéciles tournent en rond. Il faudra donc que le Divicot de notre statuaire ait les deux bras levés et appliqués contre le visage. Nous paierons un supplément.

Pendant la guerre, j'ai bien souvent pensé à Divicot. S'il avait été là, se serait-il mis du bon côté, avec les champions du Droit et de la Justice ? Cela n'est pas sûr. De son temps, la justice n'avait pas encore été inventée. Les hommes avaient alors une vigueur magnifique. C'est seulement quand les biceps se sont affaiblis, quand les vertus guerrières se sont raréfiées, que l'amour de la justice a grandi dans les cœurs. Mais qu'importent les principes pourvu qu'on divicogne?

Mesdames, Messieurs, il n'est pas sûr que notre vieux Divicot occupe une grande place dans les pensées des Vaudois d'après-guerre. Mais cela n'a aucune importance. L'enthousiasme spontané des peuples pour leurs héros a toujours été organisé par des citoyens de bonne volonté (dans mon genre). Envoyez-moi les fonds, je me charge du reste. 